\title{
AHP Decision Making Algorithm for Development of HVDC and EHVAC in Developing Countries
}

\author{
Ali Aranizadeh ${ }^{1}$, Mehrzad Kazemi², Homayoun Barahmandpour ${ }^{3}$, Hamidreza Ahady \\ Dolatsara $^{4}$
}

\begin{abstract}
Nowadays, as the population of urban areas increases, the need for consumption increases as well. This amount of consumption requires power generation centers with large volumes exploiting that it needs to be big enough, which guides technology towards bulk power transmission systems. In doing so, two types of power transmission systems, including HVDC and EHVAC, can be studied. However, since none of the above technologies has been used in developing countries, a decision should be made to introduce and develop any of these technologies. Applying both technologies together would not be cost-effective. A decision-making development needs the principles of conflicting purposes for alternatives and the selection of the best choice based on the needs of decisionmakers. Multi-objective optimization methods may well provide a solution for this selection. Thus, this paper studies deciding on the introduction and Development of HVDC and EHVAC in a developing country, Iran. To this end, measures of this selection are described in detail, and then, AHP, one of the well-known MCDM method, is used to make the final decision.
\end{abstract}

Index Terms - Bulk power transmission, Development of future infrastructures, Transmission network, Direct current system, Alterative current system

\section{INTRODUCTION}

Technology development and growth of urban life have created high centralized consumption points. To compensate this load, large volume generation centers are required, which are usually far from load points. Generation points and consumption points being far away necessitated bulk power transmission technology. However, since there are a few studies regarding experiences on construction or operation of these systems compared to lower voltage systems and considering technical, economical with environmental constraints of such systems, various studies are being done in this context. Countries that aim to enter this area normally start with pilot projects and wide developmental research. Bulk power transmission can be divided into two categories of high voltage direct current and extra-high voltage alternative current (HVDC, EHVAC). These technologies are widely used in different countries throughout the world, like the USA, China, India, Brazil, South Africa, and most European countries.

To elaborate more, most developed countries of the world formulate their transmission network development roadmap according to these technologies.

Bulk power transmission technology has not been used in Iran yet. Still, Iran has characteristics like vastness, high and concentrated electric energy consumption in large cities, electricity generation with primary carriers in large volume, and a unique strategic position in the area for electronic power transition. These facts make it a right candidate for using the bulk power transmission system for future developments.

Employing bulk power transmission technologies requires comparison studies, deciding introducing, Development of the technology, considering challenges of designing, implementing, and operating this technology beforehand. Therefore, our country must use the technical knowledge and experiences obtained in the context to employ this technology in the future. The best way to get familiar with different areas of design and operation of these technologies is to test them in pilot form and small scale before using them effectively in the network. The pilot form is introduced to the electric industry gradually through necessary scheduling for using bulk power transmission corridors, its design and operation challenges are identified to obtain the required experience for employing this technology in the electric industry. To this end, section II describes the AHP algorithm. Section III presents the measures used to decide about HVDC and EHVAC technologies. Section IV applies the AHP algorithm on the two mentioned technologies considering the decisionmaker measures, and the final analysis is made to select the technology of interest.

\section{AHP DECISION MAKING ALGORITHM}

In the science of decision making, where an approach is selected among a set of existing procedures or the criteria are prioritized, Multi Alternative Decision Making (MADM) methods have attracted attention in recent years. MADM is a sub-discipline of operations research that assesses multiple inconsistent criteria in decision making [1]. There are many MADM methods available, such as Data Envelopment Analysis (DEA). DEA has a secure link to production theory in economics and benchmarking in operations management, where a set of measures is designated to benchmark the performance of manufacturing, such as cement companies [2] and service operations in healthcare such as evaluation of

Published on June 05, 2020.

Ali Aranizadeh ${ }^{1}$, Mehrzad Kazemi ${ }^{2}$, Homayoun Barahmandpour ${ }^{3}$

123 Niroo Research Institute (NRI), Tehran-Iran.

Hamidreza Ahady Dolatsara ${ }^{4}$

Assistant Professor, Graduate School of Management, Clark University,

Worcester, MA, USA.

(Corresponding email: aaranizadeh@nri.ac.ir) 
hospital efficiency [3]. Azadeh et al. introduced Support Vector Machine (SVM) for modeling the weekly gasoline consumption in Iran Railway Network (IRN) [4]. They used Recursive Finite Newton algorithm for training SVM. Boskabadi focused on modeling and prediction of oil consumption in IRN [5]. In another effort [6] a fuzzy model for a distribution network problem was designed in a multiproduct supply chain system. In addition, [7] introduced a model to predict Iran's steel consumption in respect to economic activity using SVM. Mirmozaffari et. al combined machine learning and Optimization to extract hidden rules and remove unrelated data [8]. Meanwhile, they introduced a novel DEA model to increase the efficiency of the whole system [9]. There are many papers with computational optimization topic which can be addressed in various references [10-24].

Analytical Hierarchy Process (AHP) is one of the most well-known MADM techniques, which was first presented by Thomas L. Saaty in 1970 [25], [26]. AHP represents natural human behavior and thought. This technique studies complicated problems based on their mutual effects, simplify them, and tries to solve them. Consequently, AHP has been used in management more than other methods. AHP is based on the three following principles:

\section{A. Decomposition \\ B. Synthesis of priorities \\ C. Comparative judgments}

\section{A. Decomposition}

Since understanding a problem, in general, is difficult for humans, different and essential dimensions of a problem might be ignored. Thus, decomposing a more significant problem into smaller elements makes understanding relations, concepts of the decision-making problem, relationships between components, and the other factors easier. Decomposition creates a hierarchical tree that helps to understand and to solve problems.

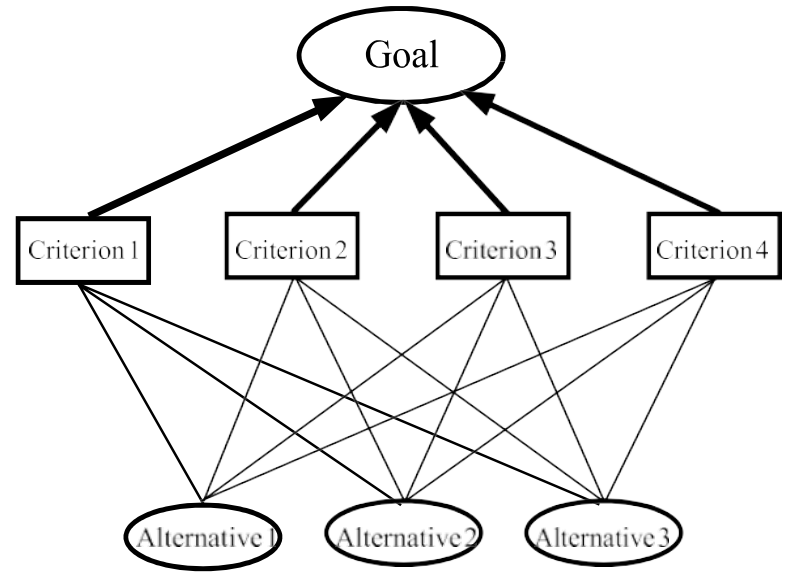

Fig.1. An example of a hierarchical process tree

The goal constitutes the first level of the hierarchy tree. The second level of the tree is the criteria (there might be more than 3 levels in some problems since some criteria might include sub-criteria). Alternatives are the bottom level. In this step, criteria and alternatives should be extracted from different resources or asked from experts. After obtaining criteria and alternatives, the problem is divided into criteria levels, sub-criteria levels (if any), and alternative levels. The criterion is an essential element in the AHP model. By creating the hierarchy tree, the hierarchy process model is not created without criteria. For instance, in Figure (1), 4 criteria and 3 alternatives constitute the hierarchy process model.

\section{B. Synthesis of Priorities}

In this step, elements of each level are compared with the corresponding parts of the higher level pairwise, and pairwise comparison matrixes are created.

To determine the importance and priorities in pairwise comparisons, spectrum 1 to 9, as represented in Table I, are used.

Table I. Values of priorities for pairwise comparisons

\begin{tabular}{|c|c|}
\hline Priorities & Value \\
\hline $\begin{array}{c}\text { Thoroughly prior or utterly more } \\
\text { important or completely more } \\
\text { favorable }\end{array}$ & 9 \\
\hline $\begin{array}{c}\text { Prior or important or very strong } \\
\text { favorability }\end{array}$ & 7 \\
\hline $\begin{array}{c}\text { Prior or important or strong } \\
\text { favorability }\end{array}$ & 5 \\
\hline $\begin{array}{c}\text { Less prior, less important or less } \\
\text { favorable }\end{array}$ & 3 \\
\hline $\begin{array}{c}\text { Prior or important or the same } \\
\text { favorability }\end{array}$ & 1 \\
\hline Priorities between the above & $2,4,6,8$ \\
\hline
\end{tabular}

\section{Comparative Judgements}

This principle represents the relationships between various criteria of one level of the hierarchy. Without a doubt, the AHP questionnaire (pairwise comparison matrix) filled out by the decision-maker may have some errors which are acceptable to some extent. However, if the error exceeds its limit, the expert should be changed, or he should be asked to fill out the form again.

\section{DECISION MAKING CRITERIA IN AHP FOR HVDC AND EHVAC TECHNOLOGIES}

Decision-making criteria for selecting HVDC and EHVAC considered in this paper are as follows:

\section{A. The justifiability of developing the technology \\ B. Ability to develop the technology \\ C. Technology requirement}

These three criteria are comprised of three sub-criteria, which are described briefly in the following sections.

\section{A. The justifiability of developing the technology}

Analyzing the surrounding environment is a proper strategic tool for recognizing a large image of the context in 
which the technology of interest is being applied. Sub-criteria of justifiability in developing the technology are as follows:

1) Future studies of the technology

2) Technology lifecycle

3) Technology market

4) The strategic position of the technology

In the following sections, the sub-criteria which affect the justifiability of HVDC and EHVAC technologies are considered.

\section{1) Future studies of the technology}

Future studies are essential tools to achieve the intelligence of technology. These studies detect and identify the most probable future innovations of human and technological development. Future studies employ a wide range of methods for systematic conjecture, which related to the future of knowledge.

The design of the DC system has reached a suitable maturity. However, there are more areas compared to the AC systems that need to be studied. Mainly, these power lines are required for long paths with a higher power, which affects the future of this technology. The pairwise comparison matrix of HVDC and EHVAC for future studies can be described in Table II

\begin{tabular}{|c|c|c|}
\multicolumn{1}{c}{} & \multicolumn{1}{c}{$\begin{array}{c}\text { Table. II. Pairwise comparison } \\
\text { matrix of the future studies }\end{array}$} \\
\cline { 2 - 3 } & EHVAC & HVDC \\
\hline EHVAC & 1 & 3 \\
\hline HVDC & $1 / 3$ & 1 \\
\hline
\end{tabular}

\section{2) Technology lifecycle}

Changing operational characteristics of the technology and reaching technical maturity throughout time describes the technology lifecycle. The technology lifecycle is a concept that shows improvement in the performance of technology throughout time. In other words, the location of technology in the lifecycle is affected by the lifecycle curves of the dependent methods. This curve has four steps, including introduction, growth, maturity, and decline.

Currently, transmission lines between 400 to $765 \mathrm{KV}$ are in the maturity phase; in fact, studies on this voltage level are finished and developed to a desirable extent. But voltage levels higher than $765 \mathrm{kV}$ up to $1500 \mathrm{kV}$ are still in the growth phase, and the technology has space for the Development.

Considering the studies performed on HVDC, extra high voltage transmission technology has passed the introduction phase, and it is being used in many countries. Allowing for the increasing trend of Development and the increasing number of extra high voltage transmission units in the world, this technology is in the growth phase, and it has not entered the maturity phase yet. The pairwise comparison matrix of HVDC and EHVAC regarding the technology lifecycle can be described in Table III.

\begin{tabular}{|c|c|c|}
\hline & EHVAC & HVDC \\
\hline EHVAC & 1 & $5 / 2$ \\
\hline HVDC & $2 / 5$ & 1 \\
\hline
\end{tabular}

\section{3) Technology market}

Many of the scientists have employed the lifecycle-market as a tool to identify strategies and policies to introduce the market. This cycle also has 4 phases, including introduction, growth, maturity, and decline. Selling a product in the introduction phase is very slow. In the growth phase, it reaches an early peak, and demand might grow slowly before declining. Along with these changes, some changes are also observed in the real growth of the competitive condition for the strategies and performance.

The pairwise comparison matrix of HVDC and EHVAC regarding the technology market can be described in Table IV.

Table. IV. Pairwise comparison matrix of the technology market

\begin{tabular}{|c|c|c|}
\cline { 2 - 3 } \multicolumn{1}{c|}{} & EHVAC & HVDC \\
\hline EHVAC & 1 & 3 \\
\hline HVDC & $1 / 3$ & 1 \\
\hline
\end{tabular}

\section{4) Strategic Position of the Technology}

Based on the strategic position, technologies can be categorized as critical or strategic and conventional technologies. "Key or Strategic" technologies are the technologies that play an essential role in realizing strategic goals. It is evident that if the strategic goal changes, key technologies also change accordingly.

In bulk power transmission technologies, HVDC plays a more strategic role compared to EHVAC since it can develop other technologies involving HVDC like wind turbine converters, solar converters, and FACTS devices. The pairwise comparison matrix of HVDC and EHVAC regarding the strategic position of the technology can be described in Table V.

Table. V. Pairwise comparison matrix of the strategic position of the technology

\begin{tabular}{|c|c|c|}
\cline { 2 - 3 } \multicolumn{1}{c|}{} & EHVAC & HVDC \\
\hline EHVAC & 1 & $5 / 2$ \\
\hline HVDC & $2 / 5$ & 1 \\
\hline
\end{tabular}

\section{B. Ability to develop the technology}

One of the most important and critical decisions making criteria is the ability to create technology. There are different sections to study this criterion:

\section{1) Possibility of cooperation with technologyowners \\ 2) Technology complexity \\ 3) Technology proportionality}

The above criteria, which affect the ability to develop HVDC and EHVAC technologies, are studied in the following sections.

\section{1) Possibility of cooperation with technology owners}

Considering the political and economic relationships of Iran, countries whose own HVDC technology is more complicated to cooperate in compared with those owning EHVAC. EHVAC exists in countries like Korea and Ukraine, with which Iran has favorable political relationships. Therefore, Iran can work with these countries to facilitate the development of these technologies in the country. The pairwise comparison matrix of HVDC and EHVAC regarding cooperation with technology owners can be described in Table VI.

Table. VI. Pairwise comparison matrix of the possibility of cooperation with technology owners 


\begin{tabular}{|c|c|c|}
\cline { 2 - 3 } \multicolumn{1}{c|}{} & EHVAC & HVDC \\
\hline EHVAC & 1 & $2 / 5$ \\
\hline HVDC & $5 / 2$ & 1 \\
\hline
\end{tabular}

\section{2) Technology Complexity}

The word "advanced technology" refers to technologies with the following characteristics:

- High complexity

- Science oriented

- Short lifecycle

- A large share of technology in the finished price of the product/service

- The high cost of research and Development

In high voltage DC transmission lines, technologies used to design and construct converters (which is the most important and most considerable part of the system) are very complicated. Thus, this technology is high.

In general, achieving an HVDC power transmission system requires high technical knowledge, and taking practical steps in this context requires creating the design, test centers, and enhancing the professional expertise of the research centers. As a result, scientific knowledge plays a more significant role compared to experience. The pairwise comparison matrix of HVDC and EHVAC regarding technology complexity can be represented in Table VII.

Table. VII. Pairwise comparison matrix of the technology complexity

\begin{tabular}{|c|c|c|}
\cline { 2 - 3 } \multicolumn{1}{c|}{} & EHVAC & HVDC \\
\hline EHVAC & 1 & 2 \\
\hline HVDC & $1 / 2$ & 1 \\
\hline
\end{tabular}

\section{3) Technology Proportionality}

Proper technology refers to the techniques which have maximum adaptability with the identified requirements on one side and existing sources (including technological sources) on the other hand. Therefore, the proper technique is not necessarily an advanced technology. The efficient and effective use of advanced technology is possible when required infrastructures and social skills exist beforehand. One of the challenges in developing countries is that it is assumed that reducing or eliminating the difference in technology level with the developed countries is possible only through transmitting advanced technologies.

Since there is proper experience at the highest available voltage level $(400 \mathrm{Kv})$, previous experiences can be used to construct and develop EHVAC lines due to the existence of technical infrastructures and scientific knowledge. Design, construction, and installation of EHVAC devices like switches and transformers are possible in Iran. But the situation of HVDC is different. Thus, it can be said that EHVAC is more proper for Iran compared to HVDC. The pairwise comparison matrix of HVDC and EHVAC regarding technology proportionality can be described in Table VIII.

\begin{tabular}{|c|c|c|}
\multicolumn{3}{c}{ complexity } \\
\cline { 2 - 3 } \multicolumn{1}{c|}{} & EHVAC & HVDC \\
\hline EHVAC & 1 & $3 / 5$ \\
\hline HVDC & $5 / 3$ & 1 \\
\hline
\end{tabular}

\section{Technology requirement}

In this section, the technologies required in the country are studied. This study is performed between HVDC and EHVAC, which has the following characteristics:

\section{1) External Corridors}

2) Internal Corridors

In the following, the sub-criteria affecting requirement to HVDC and EHVAC technologies are studied.

\section{1) External Corridors}

One of the applications of the bulk power transmission system is connecting the electricity network of Iran to the electricity network of neighboring countries. Usually, it is required to isolate networks of two states for the desired operation by connecting the two countries. Besides, since the power exchanged between two neighboring countries is controlled, HVDC is better than EHVAC. Another method is an economic measure. In some papers, EHVAC and HVDC are compared in terms of cost for constructing the line, building the station, operating the range in both technologies for the three proposed corridors. The results of this study show that the selected technology in terms of economy and line frontage in the three corridors is HVDC.

The pairwise comparison matrix of HVDC and EHVAC regarding external corridors can be described in Table IX.

Table. IX. Pairwise comparison of External connection corridors

\begin{tabular}{|c|c|c|}
\cline { 2 - 3 } \multicolumn{1}{c|}{} & EHVAC & HVDC \\
\hline EHVAC & 1 & 3 \\
\hline HVDC & $1 / 3$ & 1 \\
\hline
\end{tabular}

\section{2) Internal Corridors}

Another perspective is the requirement to GW corridors along long paths inside Iran for connecting points with the relative advantage of generation compared to the positions with excess consumption potential points. So, the cost of constructing the station, the cost of creating the line, operation cost, reliability, and line frontage is calculated to obtain the selected technology among the proposed corridors. As can be seen from the results among 5 proposed corridors, HVDC is selected in three corridors, and EHVAC is selected in 2 corridors. The pairwise comparison matrix of HVDC and EHVAC regarding the internal corridors are described as in Table X.

Table. X. Pairwise comparison matrix of the internal corridors

\begin{tabular}{|c|c|c|}
\cline { 2 - 3 } \multicolumn{1}{c|}{} & EHVAC & HVDC \\
\hline EHVAC & 1 & $1 / 2$ \\
\hline HVDC & 2 & 1 \\
\hline
\end{tabular}

Figure II shows all elements of the decision-making algorithm for selecting HVDC and EHVAC. 


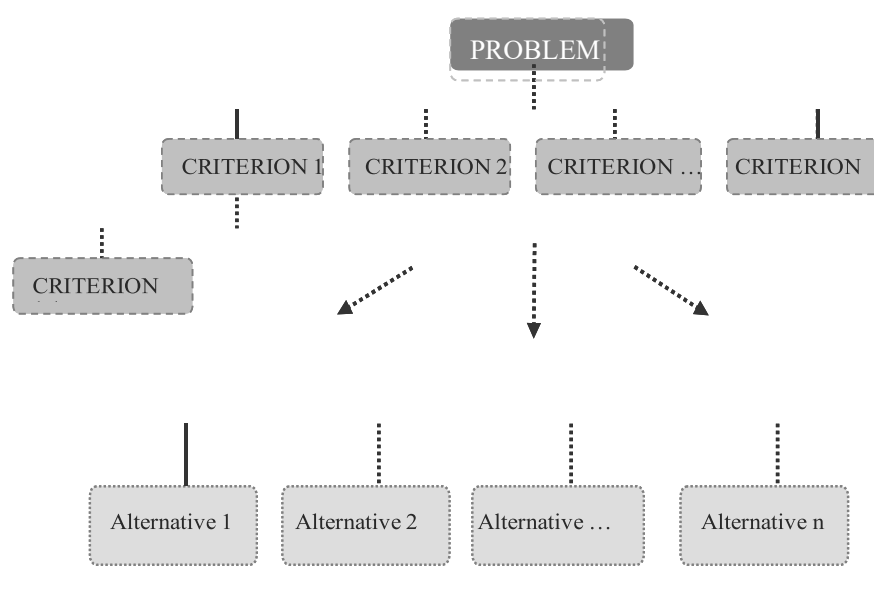

Fig. II. Hierarchical tree diagram for selecting HVDC and EHVAC

\section{IMPLEMENTING THE AHP DeCISION MAKING ALGORITHM FOR SELECTING HVDC AND EHVAC}

Table XI represents a pairwise comparison between the three main criteria of the technology type.

Table XI. Pairwise comparison among the three main criteria of the technology type

\begin{tabular}{|c|c|c|c|}
\hline Requirement & Ability & justifiability & \\
\hline $3 / 5$ & $4 / 5$ & 1 & justifiability \\
\hline $4 / 5$ & 1 & $5 / 4$ & Ability \\
\hline 1 & $5 / 4$ & $5 / 3$ & Requirement \\
\hline
\end{tabular}

Results obtained from AHP ranks show that HVDC has obtained a priority of $59.51 \%$, while EHVAC has obtained a priority of $40.49 \%$. Accordingly, HVDC is selected for Iran.

\section{CONCLUSION}

In this paper, decision making about the introduction and Development of HVDC and EHVAC technologies for future infrastructures of the country is studied. To this end, three criteria, including justifiability of the technology development, ability to develop the technology, and technology requirement, are considered. Each rule includes sub-criteria like future studies of the technology, technology lifecycle, technology market, strategic position of the technology, cooperation with technology owners, technology complexity, technology proportionality, external connections, and internal connections. After normalizing the introduced decision matrix, sub-attributes of weights with the Shannon algorithm was applied. By analyzing each criterion, sub-criteria, and generating a pairwise comparison matrix between HVDC and EHVAC using AHP algorithm, the final decision regarding selecting one of these two technologies and introducing it to Iran's network is made. As the final decision for the AHP algorithm, HVDC is selected to be organized and developed in Iran's system.

\section{REFERENCES}

[1] O. A. Gashteroodkhani, H. Askarian Abyaneh, B. Vahidi, "A new method for transmission expansion planning based on Vikor method" 29th International Power System Conference (PSC), Tehran, Iran, 2014.

[2] M. Mirmozaffari, "Eco-Efficiency Evaluation in Two-Stage Network Structure: Case Study: Cement Companies," Iranian Journal of Optimization (IJO), Dec. 16, 2018
[3] M. Mirmozaffari, and A. Alinezhad, "Ranking of Heart Hospitals Using cross-efficiency and two-stage DEA," 7th International Conference on Computer and Knowledge Engineering (ICCKE), Mashhad, pp. 217-222, 2017.

[4] A. Azadeh, A. Boskabadi, and S. Pashapour. "A unique support vector regression for improved modelling and forecasting of short-term gasoline consumption in railway systems," International Journal of Services and Operations Management, 21(2), 217-237, 2015.

[5] A. Boskabadi. "Using support vector regression (SVR) for weekly oil consumption prediction in railway transportation industry," no. December 1-12, 2011

[6] A. Boskabadi and A. Azadeh "A fuzzy model for a distribution network problem in a multi-product supply chain system," 5th national \& $3 \mathrm{rd}$ international LOGESTICS \& SUPPLY CHAIN CONFERENCE, 75-85, 2012.

[7] H. Kamalzadeh, S.N. Sobhan, A. Boskabadi, M. Hatami and A Gharehyakheh, "Modeling and Prediction of Iran's Steel Consumption Based on Economic Activity Using Support Vector Machines," arXiv preprint arXiv:1912.02373, 2019.

[8] M. Mirmozaffari, A. Boskabadi, G. Azeem, R. Massah, E. Boskabadi, H. Dolatsara and A. Liravian, "Machine learning Clustering Algorithms Based on the DEA Optimization Approach for Banking System in Developing Countries", EJERS, vol. 5, no. 6, pp. 651-658, Jun. 2020.

[9] M. Mirmozaffari, G. Azeem, A. Boskabadi, A. Aranizadeh, A. Vaishnav, and J. John, "A Novel Improved Data Envelopment Analysis Model Based on SBM and FDH Models", EJECE, vol. 4, no. 3, May 2020.

[10] M. Mirmozaffari and A. Alinezhad, "Malmquist Productivity Index Using Two-stage DEA Model in Heart Hospital, Iranian Journal of Optimization. Volume 10, Issue 2, 2018.

[11] M. Mirmozaffari, "Presenting an expert system for early diagnosis of gastrointestinal diseases," International Journal of Gastroenterology Sciences, Vol 1; Issue 1; Page 21-27, 2020.

[12] M. Mirmozaffari, "Developing an Expert System for Diagnosing Liver Diseases," EJERS, vol. 4, no. 3, pp. 1-5, Mar. 2019.

[13] M. Mirmozaffari, "Presenting a Medical Expert System for Diagnosis and Treatment of Nephrolithiasis," EJMED. May; 1:1, 2019.

[14] A. Aranizadeh, M. Kazemi, H. Berahmandpour, and M. Mirmozaffari, "MULTIMOORA Decision Making Algorithm for Expansion of HVDC and EHVAC in Developing Countries (A Case Study)," Iranian Journal of Optimization, 2020.

[15] A. Aranizadeh, I. Niazazari, and M. Mirmozaffari, "A Novel Optimal Distributed Generation Planning in Distribution Network using Cuckoo Optimization Algorithm," European Journal of Electrical Engineering and Computer Science 3 (3), 2019.

[16] S.S..Fazeli, S. Venkatachalam, R.B. Chinnam, and A. "Murat. TwoStage Stochastic Choice Modeling Approach for Electric Vehicle Charging Station Network Design in Urban Communities," IEEE Transactions on Intelligent Transportation Systems, 2020.

[17] S. Amin-Nejad, T.A. Gashteroodkhani, and Basharkhah, K., "A Comparison of MVDR and LCMV Beamformers' Floating Point Implementations on FPGAs," Wireless Personal Communications, vol. 98, no. 2, pp.1913-1929, 2018

[18] S. Amin-Nejad, K. Basharkhah, and T.A. Gashteroodkhani "Floating Point versus Fixed point Tradeoffs in FPGA Implementations of QR Decomposition Algorithm," European Journal of Electrical and Computer Engineering, vol. 3, no. 5, 2019.

[19] O.A. Gashteroodkhani, M. Majidi, M. Etezadi-Amoli “A Fuzzy-based Control Scheme for Recapturing Waste Energy in Water Pressure Reducing Valves" IEEE Power and Energy Society General Meeting (PESGM), pp. 1-5, Portland, OR, Aug 2018.

[20] M. Mirmozaffari, A. Alinezhad, and A. Gilanpour, Data Mining Apriori Algorithm for Heart Disease Prediction. Int'l Journal of Computing, Communications \& Instrumentation Engg, 4(1), pp.20-23, 2017.

[21] M. Mirmozaffari, A. Alinezhad, and A. Gilanpour, Data Mining Classification Algorithms for Heart Disease Prediction. Int'l Journal of Computing, Communications \& Instrumentation Engg, 4(1), pp.11-15, 2017.

[22] M. Mirmozaffari, A. Alinezhad, and A. Gilanpour, Heart disease prediction with data mining clustering algorithms. Int'l Journal of Computing, Communications \& Instrumentation Engg, 4(1), pp.16-19, 2017.

[23] M. Mirmozaffari, and A. Alinezhad, Window analysis using two-stage DEA in heart hospitals, October 2017

[24] M. Mirmozaffari, A. Boskabadi, G. Azeem, R. Massah, E. Boskabadi, H. Dolatsara, and A. Liravian "Machine learning Clustering Algorithms Based on the DEA Optimization Approach for Banking 
System in Developing Countries", EJERS, vol. 5, no. 6, pp. 651-658, Jun. 2020.

[25] T.L Saaty (1980) The Analytic Hierarchy Process, New York: McGraw Hill. International, Translated to Russian, Portuguese, and Chinese, Revised editions, Paperback (1996, 2000), Pittsburgh: RWS Publications.

[26] T.L Saaty (1994) 'How to make a decision: the analytic hierarchy process,' Interfaces, Vol. 24, No. 6, pp.19-43. 